\title{
Hepatoprotective Effects of Ginseng in Rats Fed Cholesterol Rich Diet
}

\author{
Deniz Uluısık \& Ercan Keskin
}

\begin{abstract}
Background: Ginseng species having been used in various traditional herbal therapies for many years in worldwide. In recent years, hyperlipidemia, hypercholesterolemia and obesity have become serious health problems. These are considered risk factor for metabolic and organic diseases such as atherosclerosis, fatty liver, diabetes. Therefore, prevention and treatment of these disorders are significant for ensuring comfortable and healthy life. It has been also stated that ginseng saponin suppressed liver enzyme increments caused by feeding with high cholesterol or fatty diet. The present study was undertaken to evaluate the effect of ginseng on liver enzymes of rats fed cholesterol-rich diet. Materials, Methods \& Results: In this study, 24 healthy adult male Wistar Albino rats were equally divided into three groups as control group (K), cholesterol group (C), and cholesterol + ginseng group (CG). The K group had ad libitum access to a standard rat diet for 40 days. The $\mathrm{C}$ and $\mathrm{CG}$ groups had ad libitum access to the same diet containing 5\% cholesterol powder and 5\% cholesterol $+1 \mathrm{~g} / \mathrm{kg}$ Panax ginseng root powder, respectively, for 40 days. On the 40 th day of the study, blood samples were taken from 8 animals in each group. At the end of the study, plasma samples were analyzed for aspartase transaminase (AST), alanine transaminase (ALT), alkaline phosphatase (ALP), and gamma-glutamyltransferase (GGT) levels. The data were analyzed using one-way ANOVA. Differences among the groups were determined by Duncan's multiple range test. In this study, the results showed that AST, ALT, GGT levels in cholesterol group significantly increased compared to control group but these parameters in cholesterol + ginseng group significantly decreased with ginseng administration compared to cholesterol group $(P<0.05)$. There was no significant difference among the groups with regard to ALP level.

Discussion: AST, ALT, GGT and ALP are considered to be the markers of organ disfunction, indicator of cellular damage, cell leakage and the loss of cell membrane integritiy in the liver, kidney, heart and other organs. It was investigated effect of ginseng on some hepatic enzymes in rats fed a high cholesterol diet. In this study, feeding with the diet for 40 days resulted in elevation AST, ALT, GGT compared control levels $(P<0.05)$. In some studies, using high cholesterol diet caused hepatic injury in animal and human models. The harmful effects of high cholesterol on liver have been attributed to hepatic fibrosis, lipid peroxidation, increased endogenous oxidative stress, inducing cellular damage and engendering hyperlipidemia. Increases in ALT, AST, GGT levels are thought to be due to oxidative stress related to hyperlipidemia in present study. In this study, treated with red Korean ginseng extract significantly prevented the elevations in AST, ALT, GGT levels $(P<0.05)$. The use of ginseng as an unconventional health treatment is gaining remarkable popularity among the people. It has been known that ginseng have assorted beneficial pharmacological effects and hypolipidemic, antidiabetic, antioxidative and immunostimulator effects have been stated among its pharmacological properties. These beneficial effects of ginseng on liver enzymes attributed to its active components known as ginsenosides. In the light of the findings, Panax ginseng root powder may be useful for hepatic damage and fibrosis associated with high cholesterol diet.
\end{abstract}

Keywords: ginseng, cholesterol, liver enzyme, rat. 


\section{INTRODUCTION}

Hypercholesterolemia has been accepted as an important risk factor for coronary heart disease and atherosclerosis $[5,40]$. Cholesterol rich diet causes the quick deposition of lipid droplets in the liver [3]. Lipid accumulation results from an imbalance between hepatic fatty acid inflow, triglyceride synthesis and excretion. Therefore, lipid droplets are primarily stored as triglyceride [1]. There is an association between high cholesterol or fatty diet and hepatic injury as reported in previous study conducted in rabbit and rat models $[4,7,45]$. The harmful effects of cholesterol on liver and the relationship between receiving a high cholesterol diet and hepatic fibrosis just has not been well understood. It has been suggested that myofibroblasts play primarily role in hepatic fibrosis. On the other hand, macrophages and mast cells participate in this process [14-16].

Ginseng (Panax ginseng C. A. Meyer, family Araliaceae) as medical plant has been commonly used in East Asian countries. Ginsenosides are the major components of ginseng [43]. These ginsenosides have various biological properties such as anti-inflammatory [46], anti-allergic [36], hypoglycemic and antidiabetic $[23,34,42]$, hypocholesterolemic and hypolipidemic [26], anticarcinogenic $[30,44,50]$ and hepatoprotective activities [13,28,29,48].

Thus, it was the aim of this study to investigate the effect of ginseng on some liver enzymes (AST, ALT, ALP and GGT) in rats that were fed high cholesterol diet.

\section{MATERIALS AND METHODS}

In this study, 24 healthy adult male Wistar Albino rats were equally divided into three groups as control group (K), cholesterol group (C), and cholesterol + ginseng group (CG). The K group had ad libitum access to a standard rat diet $\left(\text { Purina }^{\circledR}\right)^{1}$ for 40 days. The $\mathrm{C}$ and $\mathrm{CG}$ groups had ad libitum access to the same diet containing 5\% cholesterol powder ${ }^{2}$ and $5 \%$ cholesterol $+1 \mathrm{~g} / \mathrm{kg}$ Panax Ginseng root powder ${ }^{3}$, respectively, for 40 days. On the 40 th day of the study, blood samples were taken from 8 animals in each group. In plasma samples, AST, ALT, ALP, GGT were determined in an ILAB 300 autoanalyser using ILAB300 kits.

\section{Statistical analysis}

The data were analyzed using one-way ANOVA (SPSS 17). Differences among the groups were determined by Duncan's multiple range test. Differences were considered significant at $P<0.05$.

\section{RESULTS}

At the end of 40 th day, AST, ALT, ALP, GGT levels in rats were presented in Table 1. In this study, AST, ALT, GGT levels in cholesterol group significantly increased with feeding high cholesterol diet compared to control group $(P<0.05$, Table 1$)$. Although, there are obviously increases in ALP level, difference is not important. The administration of ginseng to the high cholesterol diet significantly prevented elevations of AST, ALT, GGT levels compared to cholesterol group $(P<0.05$, Table 1$)$.

Table 1. Effect of ginseng on plasma AST, ALT, ALP and GGT levels in rats fed cholesterol rich diet $(\mathrm{Mean} \pm \mathrm{SE})$.

\begin{tabular}{ccccc}
\hline $\begin{array}{c}\text { Group } \\
(\mathrm{n}=8)\end{array}$ & $\begin{array}{c}\text { AST } \\
\mathrm{U} / \mathrm{L}\end{array}$ & $\begin{array}{c}\text { ALT } \\
\mathrm{U} / \mathrm{L}\end{array}$ & $\begin{array}{c}\text { ALP } \\
\mathrm{U} / \mathrm{L}\end{array}$ & $\begin{array}{c}\text { GGT } \\
\mathrm{U} / \mathrm{L}\end{array}$ \\
\hline $\mathrm{K}$ & $77.13 \pm 4.84^{\mathrm{b}}$ & $29.38 \pm 2.58^{\mathrm{b}}$ & $87.75 \pm 6.40$ & $8.16 \pm 0.74^{\mathrm{b}}$ \\
$\mathrm{C}$ & $101.25 \pm 4.22^{\mathrm{a}}$ & $38.75 \pm 3.02^{\mathrm{a}}$ & $103.13 \pm 4.85$ & $11.20 \pm 0.56^{\mathrm{a}}$ \\
$\mathrm{CG}$ & $86.88 \pm 5.08^{\mathrm{b}}$ & $30.63 \pm 1.40^{\mathrm{b}}$ & $93.63 \pm 6.66$ & $9.24 \pm 0.49^{\mathrm{b}}$ \\
\hline
\end{tabular}

The difference between mean values with different superscripts in the same column is significant at the $P<0.05$ level. 


\section{DISCUSSION}

In this study, we investigated effect of ginseng on some hepatic enzymes in rats fed a high cholesterol diet. Feeding with the diet for 40 days resulted in elevation AST, ALT, GGT compared control levels $(P<$ 0.05 , Table 1$)$. In many studies, using a manipulated high cholesterol diet caused hepatic injury in animal and human models $[10,11,17]$. The hazardous effects of cholesterol itself on the liver have been attributed to hepatic fibrosis, lipid peroxidation, increased endogenous oxidative stress, inducing cellular damage and engendering hyperlipidemia [15,16,33,41]. In our study, increases in ALT, AST, GGT levels are thought to be due to oxidative stress related to hyperlipidemia [6,9]. These enzymes are considered to be the markers of organ disfunction, indicator of cellular damage, cell leakage and the loss of cell membrane integritiy in the liver, kidney, heart and other organs [24,38,39,47].

It has been known that ginseng have assorted beneficial pharmacological effects and hypolipidemic, antidiabetic, antioxidative and immunostimulator effects have been stated among its pharmacological properties $[2,49]$. Ginseng products such as saponin type ginsenosides and non-saponin type poliacetylene panaxatriol, panaxadiol, oxidative polysaccharides and amino acids are responsible for its hypolipidemic and hypocholesterolemic effects [21,22,27]. It has been noted that ginseng treatments obviously decreased serum cholesterol and triglyceride levels in hyperlipidemic monkeys [8]. Hwang et al. [12] reported that ginseng saponins supplementation diminished the serum cholesterol level in rabbits fed with high cholesterol diet. On the other hand, it has been stated that ginsenosides have protective properties on cellular damage and membrane stabilities in several tissue $[18,35]$. In this study, treated with red Korean ginseng extract significantly prevented the elevations in AST, ALT, GGT levels $(P<0.05$, Table 1$)$. In paralelly with our findings, Kalkan et al. [18] observed that ginseng treatment significantly suppressed the increment in serum AST, ALT and GGT activities. Another study reported that crude ginsenosides extracted from stems and leaves of American ginseng reduced pancreatic lipase activity (in vitro), the plasma lipids and parametrial adipose tissue weights in mice which feeding a high fat diet [32]. Also, some studies have suggested evidences about the protective effects of ginseng on kidney and liver damage [19,20,37]. However, it has been reported that ginsenosides are responsible for its hepatoprotective effect by destroy lipid peroxyl radicals and reactive oxygen species [25]. Liu et al. [31] demonstrated that American ginseng has effective roles in preventing of obesity, fatty liver and hypertriglyceridemia in mice fed with a high-fat diet.

In conclusion, our findings suggest that Panax ginseng root powder can prevent hepatic damage and fibrosis following feeding with high cholesterol diet. In our study, the reducing effect of ginseng on these enzymes might be related with both its hypocholesterolemic and antioxidative effect.

\section{MANUFACTURERS \\ ${ }^{1}$ Optima Besin Maddeleri San. ve Tic. A.Ş. Balıkesir, Turkey. \\ ${ }^{2}$ Sigma-Aldrich. Steinheim, Germany. \\ ${ }^{3}$ General Nutrition Products (GNC) Inc. Greenville, SC, USA.}

Ethical approval. All experimental procedures were approved (number 2014/39) by the Ethical Committee of S.U. Veterinary Faculty, Konya, Turkey.

Declaration of interest. The authors report no conflicts of interest. The authors alone are responsible for the content and writing of the paper.

\section{REFERENCES}

1 Alpers D.H., Sabesin S.M. \& White H.M. 1993. Fatty liver: biochemical and clinical aspect. In: Schiff L. \& Schitt E.R. (Eds). Diseases of liver. 7th edn. Philadelphia: J.B. Lippincott Co., pp.825-871.

2 Attele A.S., Wu J.A. \& Yuan C.S. 1999. Ginseng pharmacology: multiple constituents and multiple actions. Biochemical Pharmacology. 58(11): 1685-1693.

3 Burt A.D., Mutton A. \& Day C.P. 1998. Diagnosis and interpretation of steatosis and steatohepatitis. Seminars in Diagnostic Pathology. 15(4): 246-258.

4 Buyssens N., Kockx M.M., Herman A.G., Lazou J.M., Van den Berg K., Wisse E. \& Geerts A. 1996. Centrolobular liver fibrosis in the hypercholesterolemic rabbit. Hepatology. 24(4): 939-946.

5 Castelli W.P., Garrison R.J., Wilson P.W., Abbott R.D., Kalousdian S. \& Kannel W.B. 1986. Incidence of coronary heart disease and lipoprotein cholesterol levels. The Framingham Study. The Journal of the American Medical Association. 256(20): 2835-2838. 
6 Cho H.C. 2010. The association between serum GGT concentration and diabetic peripheral polyneuropathy in type 2 diabetic patients. Korean Diabetes Journal. 34(2): 111-118.

7 Del Moral M.L., Esteban F.J., Torres M.I., Camacho M.V., Hernandez R., Jimenez A., Aranega A., Pedrosa J.A. \& Peinado M.A. 1997. High-fat sunflower and olive oil diets affect serum lipid levels in steatotic rat liver differently. Journal of Nutritional Science and Vitaminology. 43(1): 155-160.

8 Dixit V.R., Jain P., Bhandari K. \& Purohit A.K. 1991. Effects of ginseng (G-115) serum lipids of hyperlipidaemic rhesus monkeys (Macaca mulatta). Indian Journal of Pharmaceutical Sciences. 53(3): 88-91.

9 Drozdz R., Parmentier C., Hachad H., Leroy P., Siest G. \& Wellman M. 1998. Gamma-glutamyltransferase dependent generation of reactive oxygen species from a glutsthione/transferrin system. Free Radical Biology and Medicine. 25(7): 786-792.

10 Farrell G.C. \& Larter C.Z. 2006. Nonalcoholic fatty liver disease: from steatosis to cirrhosis. Hepatology. 43(2 suppl 1): 99-112.

11 Ferre N., Martinez-Clemente M., Lopez-Parra M., Gonzalez-Periz A., Horrillo R., Planaguma A., Camps J., Joven J., Tres A., Guardiola F., Bataller R., Arroyo V. \& Claria J. 2009. Increased susceptibility to exacerbated liver injury in hypercholesterolemic ApoE-deficient mice: potential involvement of oxysterols. American Journal of Physiology Gastrointestinal Liver Physiology. 296(3): 553-562.

12 Hwang S.Y., Son D.J., Kim I.W., Kim D.M., Sohn S.H., Lee J.J. \& Kim S.K. 2008. Korean red ginseng attenuates hypercholesterolemia-enhanced platelet aggregation through suppression of diacylglycerol liberation in high-cholesteroldiet-fed rabbits. Phytotherapy Research. 22(6): 778-783.

13 Jeong T.C., Kim H.J., Park J.I., Ha C.S., Park J.D., Kim S.I. \& Roh J.K. 1997. Protective effects of red ginseng saponins against carbon tetrachloride-induced hepatoxicity in Spargue Dawley rats. Planta Medica. 63(2): 136-140.

14 Jeong W.I., Jeong D.H., Do S.H., Kim Y.K., Park H.Y., Kwon O.D., Kim T.H. \& Jeong K.S. 2005. Mild hepatic fibrosis in cholesterol and sodium cholate diet-fed rats. Journal of Veterinary Medical Science. 67(3): 235-242.

15 Jeong W.I., Lee C.S., Park S.J., Chung J.Y. \& Jeong K.S. 2002. Kinetics of macrophages, myofibroblasts and mast cells in carbon tetrachloride-induced rat liver cirrhosis. Anticancer Research. 22(2A): 869-877.

16 Johnson S.J., Hines J.E. \& Burt A.D. 1992. Macrophage and perisinusoidal cell kinetics in acute liver injury. The Journal of Pathology. 166(4): 351-358.

17 Jou J., Choi S.S. \& Diehl A.M. 2008. Mechanisms of disease progression in nonalcoholic fatty liver disease. Seminars in Liver Disease. 28(4): 370-379.

18 Kalkan Y., Kapakin K.A.T., Kara A., Atabay T., Karadeniz A., Simsek N., Karakus E., Can I., Yildirim S., Ozkanlar S. \& Sengul E. 2012. Protective effect of Panax ginseng against serum biochemical changes and apoptosis in kidney of rats treated with gentamicin sulphate. Journal of Molecular Histology. 43(5): 603-613.

19 Karadeniz A., Cemek M. \& Simsek N. 2009. The effects of Panax ginseng and Spirulina platensis on hepatotoxicity induced by cadmium in rats. Ecotoxicology and Environmental Safety. 72(1): 231-235.

20 Karadeniz A., Yıldırım A., Karakoc A., Kalkan Y. \& Celebi F. 2009. Protective effect of Panax ginseng on carbon tetrachloride induced liver, heart and kidney injury in rats. Revue de Médecine Vétérinaire. 160(5): 237-243.

21 Kim D.J., Seong K.S., Kim D.W., Ko S.R. \& Chang C.C. 2004. Antioxidative effects of red ginseng saponins on paraquat-induced oxidative stress. Journal of Ginseng Research. 28(1): 5-10.

22 Kim H.J., Lee S.G., Chae I.G., Kim M.J., Im N.K., Yu M.H., Lee E.J. \& Lee I.S. 2011. Antioxidant effects of fermented red ginseng extracts in streptozotocin-induced diabetic rats. Journal of Ginseng Research. 35(2): 129-137.

23 Kim K. \& Kim H.Y. 2008. Korean red ginseng stimulates insulin release from isolated ratpancreatic islets. Journal of Ethnopharmacology. 120(2): 190-195.

24 Kim Y.S., Kim Y.H., Noh J.R., Cho E.S., Park J.H. \& Son H.Y. 2011. Protective effect of Korean red ginseng against aflatoxin B1-induced hepatotoxicity in rat. Journal of Gin-seng Research. 35(2): 243-249.

25 Kitts D.D. \& Hu C. 2000. Efficacy and safety of ginseng. Public Health Nutrition. 3(4A): 473-485.

26 Kwak Y.S., Kyung J.S., Kim J.S., Cho J.Y. \& Rhee M.H. 2010. Antihyperlipidemic effects of red ginseng acidic polysaccharides from Korean red ginseng. Biological and Pharmaceutical Bulletin. 33(3): 468-472.

27 Lee C.K., Choi J.W., Kim H. \& Han Y.N. 1999. Biological activities of acidic polysaccharide of Korean red ginseng. II. Effects on hyperlipidemia induced by alcohol. Journal of Ginseng Research. 23(1): 8-12.

28 Lee H.U., Bae E.A., Han M.J. \& Kim D.H. 2005. Hepatoprotective effect of 20(S) ginsenosides Rg3 and its metabolite 20(S)-ginsenoside Rh2 on tert-butyl hydroperoxide-induced liver injury. Biological and Pharmaceutical Bulletin. 28(10): 1992-1994. 
29 Lee H.U., Bae E.A., Han M.J., Kim N.J. \& Kim D.H. 2005. Hepatoprotective effect of ginsenoside Rb1 and compound K on tert-butyl hydroperoxide-induced liver injury. Liver International. 25(5): 1069-1073.

30 Lee S.J., Sung J.H., Lee S.J., Moo C.K. \& Lee B.H. 1999. Antitumor activity of a novel ginseng saponin metabolite in human pulmonary adenocarcinoma cells resistant to cisplatin. Cancer Letters. 144(1): 39-43.

31 Liu R., Zhang J., Liu W., Kimura Y. \& Zheng Y. 2010. Anti-obesity effects of protopanaxdiol types of ginsenosides isolated from the leaves of American ginseng (Panax quinquefolius L.) in mice fed with a high-fat diet. Fitoterapia. 81(8): 1079-1087.

32 Liu W., Zheng Y., Han L., Wang H., Saito M., Ling M., Kimura Y. \& Feng Y. 2008. Saponins (Ginsenosides) from stems and leaves of Panax quinquefolium prevented high-fat diet-induced obesity in mice. Phytomedicine. 15(12): 1140-1145.

33 Lones T.J. 1991. Oxidized low density lipoproteins: a role in the pathogenesis of atherosclerosis in diabetes ? Diabetes Medicine. 8(5): 411-419.

34 Ng T.B. \& Yeung H.W. 1985. Hypoglycemic constituents of Panax ginseng. General Pharmacology. 16(6): 549-552.

35 Park E., Hwang I., Song J.Y. \& Jee Y. 2011. Acidic polysaccharide of Panax ginseng as a defense against small intestinal damage by whole-body gamma irradiation of mice. Acta Histochemica. 113(1): 19-23.

36 Park E.K., Choo M.K., Han M.J. \& Kim D.H. 2004. Ginsenoside Rh1 possesses antiallergic and anti-inflammatory activities. International Archives of Allergy and Immunology. 133(2): 113-120.

37 Park W.H., Lee S.K. \& Kim C.H. 2005. A Korean herbal medicine, Panax notoginseng, prevents liver fibrosis and hepatic microvascular dysfunction in rats. Life Sciences. 76(15): 1675-1690.

38 Ramesh T., Kim S.W., Hwang S.Y., Sohn S.H., Yoo S.K. \& Kim S.K. 2012. Panax ginseng reduces oxidative stress and restores antioxidant capacity in aged rats. Nutrition Research. 32(9): 718-726.

39 Ramesh T., Kim S.W., Sung J.H., Hwang S.Y., Sohn S.H., Yoo S.K. \& Kim S.K. 2012. Effect of fermented Panax ginseng extract (GINST) on oxidative stress and antioxidant activities in major organs of aged rats. Experimental Gerontology. 47(1): 77-84.

40 Ronnemaa T., Pelliniemi T.T. \& Kulonen E. 1976. Factors stimulating collagen synthesis from the livers of hypercholesterolemic rats. Atherosclerosis. 24(1-2): 311-321.

41 Tai E.S., Lim S.C., Tan B.Y., Chew S.K., Heng D. \& Tan C.E. 2000. Screening for diabetes mellitus: a two-step approach in individuals with impaired fasting glucose improves in detection of those at risk of complications. Diabetes Medicine. 17(11): 771-775.

42 Takaku T., Kameda K., Matsuura Y., Sekiya K. \& Okuda H. 1990. Studies on insulin like stances in Korean red ginseng. Planta Medica. 56(1): 27-30.

43 Tanaka N., Tanaka O. \& Shibata S. 1972. Chemical studies on the oriental plant drugs. XXVIII. Saponins and sapogenins of ginseng; Stereochemistry of sapogenin of ginsenoside Rb1, Rb2 and Rc. Chemical and Pharmaceutical Bulletin. 20(6): 1212-1216.

44 Wakabayashi C., Hasegewa H., Murata J. \& Saiki I. 1997. In vivo antimetastatic action of ginseng protopanaxadiol saponins is based on their intestinal bacterial metabolites after oral administration. Oncology Research. 9(8): 411-417.

45 Wanless I.R., Belgiorno J. \& Huet P.M. 1996. Hepatic sinusoidal fibrosis induced by cholesterol and stilbestrol in the rabbit: 1. Morphology and inhibition of fibrogenesis by dipyridamole. Hepatology. 24(4): 855-864.

46 Wu J.Y., Gardner B.H., Murphy C.I., Seals J.R., Kensil C.R., Recchia J., Beltz G.A., Newman G.W. \& Newman M.J. 1992. Saponin adjuvant enhancement of antigen-specific immune responses to an experimental HIV-1 vaccine. The Journal of Immunology. 148(5): 1519-1525.

47 Yokozawa T., Kim H.Y., Kim H.J., Tanaka T., Sugino H., Okubo T., Chu D.C. \& Juneja L.R. 2007. Amla (Emblica officinalis Gaertn.) attenuates age-related renal dysfunction by oxidative stress. Journal of Agricultural and Food Chemistry. 55(19): 7744-7752.

48 Yoshikawa M., Morikawa T., Kashima Y., Ninomuya K. \& Matsuda H. 2003. Structures of new dammarane-type triterpene saponins from the flower buds of Panax notoginseng and Hepatoprotective effects of principal ginseng saponins. Journal of Natural Products. 66(7): 922-927.

49 Yun S.H. \& Joo C.N. 1993. Study on the preventive effect of ginsenosides against hypercholesterolemia and its mechanism. Korean Journal of Ginseng Science. 17(1): 1-12.

50 Yun T.K., Lee Y.S., Lee Y.H., Kim S.I. \& Yun H.Y. 2001. Anticarcinogenic effect of Panax ginseng and identification of active compounds. Journal of Korean Medical Science. 16(S): 6-18. 